
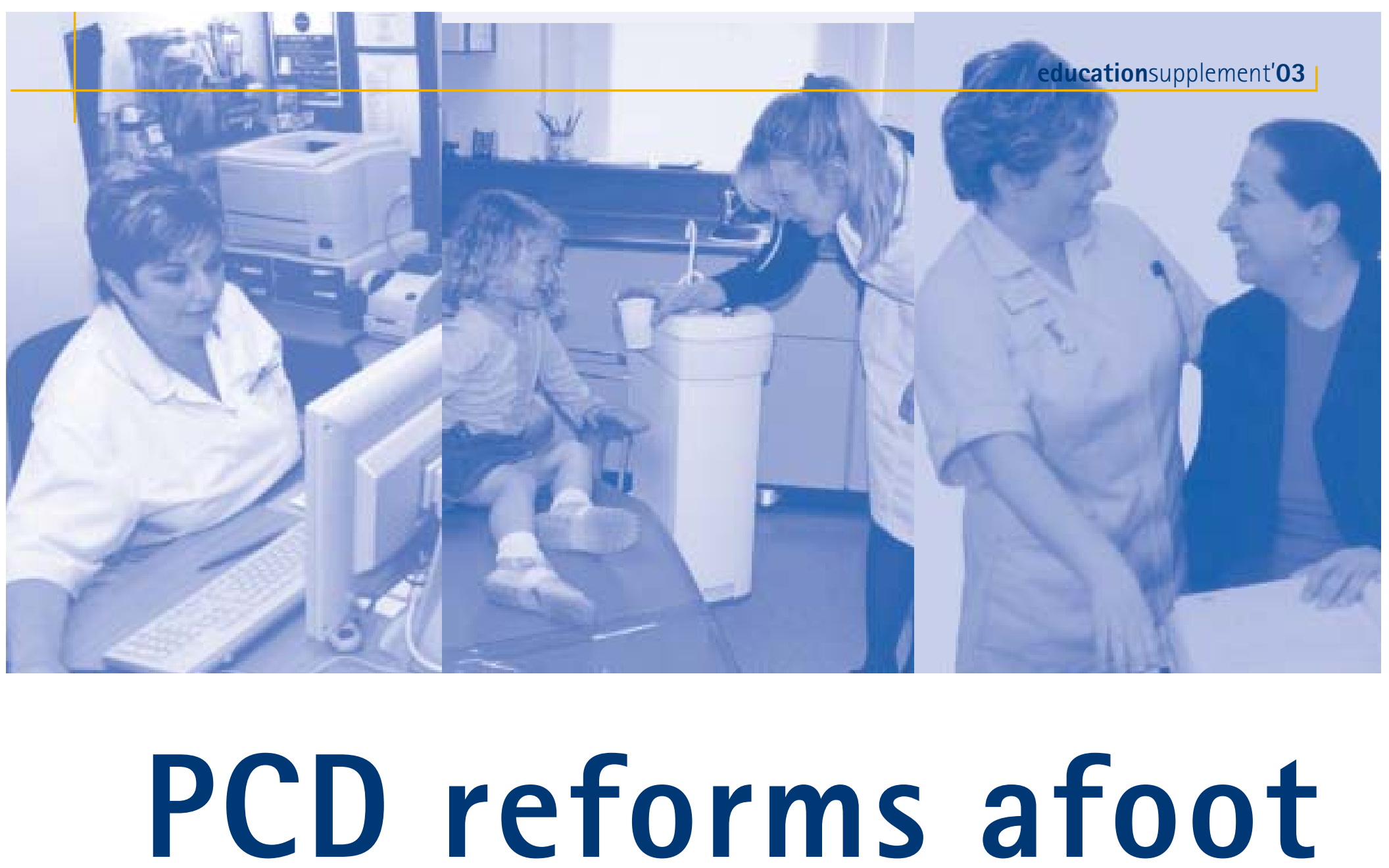

Changes to

4 the regulation of PCDs will

have

important

implications

for dentists,

reports

GORDON

WATKINS
$\mathrm{M}$ ajor changes are afoot regarding the regulation of Professionals Complementary to Dentistry (PCDs) changes that will have important implications for dentists.

Since 1999 the General Dental Council (GDC) has been committed to implementing a series of reforms in respect of PCDs. The first of these came into effect on 1 July 2002, when the duties of dental hygienists and dental therapists were significantly extended (see box 1).

The GDC currently plans to implement further, more far-reaching, PCD reforms. The implementation date for these has been given as autumn 2004 - but this is highly provisional. A draft Order under s. 60 of the Health Act 1999 has first to be published, following which a three-month statutory consultation must take place. Parliamentary time will then have to be found for the Order to be debated and voted on.

This set of reforms is planned to introduce:

- mandatory GDC registration for all PCDs involved in clinical activity, including dental nurses and dental technicians (for whom there have hitherto only been voluntary registers);

- two new classes of PCD - "orthodontic therapists" (working under the direction of orthodontists) and "clinical dental technicians"; and

- a new regulatory framework for PCDs.

Under the current regulatory framework (enshrined in Parts IV and V of the Dentists Act
1984), procedures amounting to the practice of dentistry can only be carried out by a registered dentist or by an enrolled dental hygienist or therapist. The latter may only perform those duties explicitly prescribed in the appropriate part of the Dental Auxiliaries Regulations 1986 (as subsequently amended), made by Parliament under the 1984 Act. Regulation 23 covers hygienists' duties and Regulation 27 covers those of therapists.

The existing regulations state that hygienists and therapists may only carry out permitted dental work under the direction of a registered

\section{BOX 2:}

The GDC's policy is that the entry-level qualifications for dental nurse registration will be:

- National Certificate awarded by the National Examining Board for Dental Nurses;

- National Vocational Qualification (NVQ) - SVQ in Scotland - Oral Healthcare Dental Nursing Level 3;

- Certificate of Proficiency in Dental Nursing awarded by a dental hospital which is recognized by the Association of Dental Hospitals.

The title "dental nurse" will be reserved to people with these qualifications, plus those admitted under the transitional arrangements.

The following transitional qualifications will be accepted for entry onto the mandatory register for two years after it opens: 


\section{BOX 1:}

In July 2002, both hygienists and therapists were additionally permitted to:

- remove excess cement using instruments (including rotary instruments);

- take impressions;

- give ID block anaesthesia under the direct personal supervision of a dentist:

- administer local infiltration anaesthesia without the direct personal supervision of a dentist;

- undertake emergency replacement of crowns with a temporary cement; and

- treat patients under conscious sedation provided that a dentist remains in the room throughout the treatment.

At the same time, therapists were additionally permitted to:

- undertake pulp therapy; and

- place pre-reformed crowns on primary teeth.

Also, therapists were allowed to work in all sectors of dentistry without restriction, meaning that they were at last permitted to work in General Dental Services.

Hygienists and therapists may only undertake extended duties once they have received the necessary training. It is the responsibility of the employing or supervising dentist, as the leader of the dental team, to ensure that hygienists and therapists are appropriately trained. The GDC's ethical guidance, Maintaining Standards, states that "A dentist should employ suitably trained and, where appropriate, qualified staff" (para. 5.1).

Training in the extended duties is provided by the dental schools and dental hospitals, as well as by postgraduate centres. Courses should be taught by:

- suitably trained dental hygiene or dental therapy tutors:

- dentally qualified tutors with experience of teaching dental hygiene or dental therapy students; or

- registered dentists with experience of teaching these duties to dental undergraduate or postgraduate students.

Lists of courses are available on the British Dental Hygienists Association website at http://www.bdha.org.uk. Any problems in accessing courses in extended duties should be raised with the local postgraduate dental dean (details are available here: http://www.copdend.org.uk).

The schools of dental hygiene and dental therapy all have training programmes for the extended duties. Upon successful completion of a course in extended duties, a certificate of completion of training will be issued. There is no need to notify the GDC, but the certificate should be retained as proof. dentist, and after the dentist has examined the patient and indicated in writing to the hygienist or therapist the treatment to be provided.

Under the proposed reforms, regulation through prescriptive lists of permitted duties will be replaced by regulation through educational curricula and ethical guidance (i.e. Maintaining Standards). Only GDC registrants will be permitted to practise dentistry. The GDC will hold two separate registers, one for dentists and one for PCDs. Entry to the PCD register will be on the basis of curricula and qualifications recognised and regulated by the GDC (and, as a transitional

\section{"A dentist should employ suitably trained and, where appropriate, qualified staff."}

- National Certificate awarded by the National Examining Board for Dental Surgery Assistants;

- Certificate of Proficiency in Dental Surgery Assisting awarded by a dental hospital which is recognized by the Association of Dental Hospitals;

- BTEC National Certificate in Science (Dental Surgery Assisting or Dental Nursing);

- Full SCOTVEC Certificate in Dental Surgery Assisting or Dental Nursing;

- Royal Navy - Part III DSA Training (Certified);

- Army - Class 2 Dental Clerk Assistant Trade Training;

- Royal Air Force - DSA Training and Trade Ability Test B;

- Dental Defence Agency - Basic Dental Nurse Training and Individual Development Portfolio Stage 1 (IDPS1) measure for established PCD groups, relevant validated experience). Certain titles (dental hygienist, dental therapist, dental nurse, dental technician, clinical dental technician, maxillofacial prosthetist and technologist, and orthodontic therapist) will be reserved by law to those who become registered.

There will be a statutory requirement that, in undertaking work amounting to the practice of dentistry, PCDs must work under the authority of a dentist. Every registrant will be responsible to the GDC for practising within the limits of their competence, and for the procedures undertaken. Dentists will be additionally responsible to the GDC for ensuring that colleagues in teams they lead do not, and are not asked to, undertake practice beyond their competence.

PCD educational curricula will define the knowledge, skills and aptitudes that a PCD must have on first registration. There will be no barriers to PCDs expanding their range of skills through recognised training and experience. A modular approach across PCD training routes will be encouraged.

There will be clear ethical guidance to dentists and PCDs on their roles and responsibilities. There will be integration of PCD regulation into the work of the GDC, to include regulation of all dental education, compulsory CPD for all registrants, and common fitness-to-practise procedures (conduct, health and performance) for all registrants.

All PCDs on the PCD register will be required to undertake a compulsory minimum number of hours of Continuing Professional Development, but the precise details have yet to be established. 
"there will continue to

be a clear distinction between PCDs and dentists. Dentists will continue to be the lead members of the dental team; and dentists will continue to be the 'gatekeepers' of dental services"
It is intended that there will continue to be a clear distinction between PCDs and dentists. Dentists will continue to be the lead members of the dental team; and dentists will continue to be the 'gatekeepers' of dental services - it will still be the case that no patient will see a PCD without first seeing a dentist. Nevertheless, there will be considerably more scope for flexibility within the new regulatory framework than exists at present.

The statutory registration of dental nurses will have a big impact on dental practices. The BDA is working hard to try and ensure that registration is introduced on terms that will benefit dental nurses, dental practices and patients. A key issue is the type of qualification that nurses will need to have in order to be entered on the register (see box 2).

Dental nurses whose names are on the current voluntary register (maintained by the Dental Nurses Standards and Training Advisory Board) will be eligible for direct entry onto the mandatory register when it first opens.

It is proposed that dental nurses who have no formal qualifications but who can demonstrate proven experience of working satisfactorily as a dental nurse for a period of at least four years full-time (or the equivalent period part-time) in the previous eight years will be eligible to enter under the transitional arrangements.

It is also proposed that, in exceptional circumstances, dental nurses who do not meet the above criteria may be eligible to register after some form of individual assessment under the transitional arrangements. The details of this have yet to be decided.

Applications under these transitional arrangements must be made within two years of the date

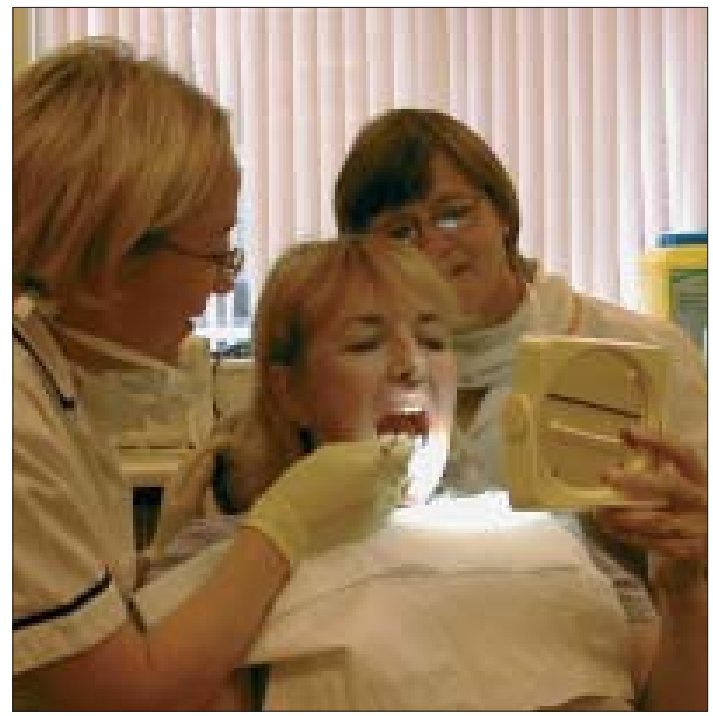

of establishment of the mandatory PCD register.

Dentists are advised to ensure as soon as possible that the nurses they employ are qualified for registration or are working towards a registrable qualification, if they are not covered by the transitional arrangements. For information on accessing NVQ courses, see box 3.

For more information, contact:

the PCD team at the GDC - tel.: 02078873800 or email:PCDs@gdc-uk.org;

the Professional Services Directorate at the BDA tel.: 02075634199 or e-mail:m.fraser@bda.org.

\section{BOX 3:}

\section{Dental nurse NVOs}

Some NVQ courses are listed on the Learn Direct website: http://www.learndirect-advice.co.uk/findacourse. The National Examining Board for Dental Nurses has a List of Dental Nurse Training Providers and a List of NVO Approved Assessment Centres; copies of both are held by the Policy Directorate and the Professional Services Directorate at BDA headquarters. It is also worth asking local colleges and other NVQ / SVQ providers what courses they have on offer.

A distance-learning package is available in the form of Teamwork, which is published by the Faculty of General Dental Practitioners: http://www.rcseng.ac.uk/dental/fgdp/publications/ teamwork_6_html.

The cost of NVQ courses varies a great deal. Prices between $£ 500$ and $£ 1,200$ have been advertised. It is advisable to shop around for a good deal, while ensuring that the course you get meets both the nurse's and the practice's needs.

There is now automatic Learning and Skills Council (LSC) funding for NVOs / SVOs for under-18s, which is obtained through the assessment centre (in Scotland, this money comes from Local
Enterprise Companies rather than the LSC). The whole cost of the course is covered and the money goes to the course provider. In the case of 18-25-year-olds, the training provider applies for a grant to cover all or part of the training costs. Funding is variable depending on the assessment centre and the regional LSC funding center (the funding on offer ranges from a few hundred pounds to as much as $£ 2,000$ ), which may not be sufficient to cover all the costs. Details of local LSCs are available here: http://www.lsc.gov.uk/localarms.cfm.

In England, some funding should be available from NHS Workforce Development Confederations (WDCs; now part of Strategic Health Authorities), as dental nurse training is included within the current scope of the Non-Medical Education and Training Budget (NMET), and the Medical and Dental Education Levy (MADEL) component of the Multi-Professional Education and Training Budget (MPET). This is the only government funding available for dental nursing NVQ candidates aged over 25. Details of WDCs are available from the WDCs' Standing Conference: http://www.wdc.nhs.uk/confed_contact_details/index.php.

More information about NVQs is available in BDA Advice Note 4, National Vocational Qualifications for Dental Nurses, which can be obtained by members, free of charge, from the Professional Services Directorate. 